\title{
Direct detection of diclofenac radical produced by ultraviolet irradiation using electron spin resonance method
}

\author{
Satomi Akazaki,* Ryohei Aoki and Keizo Sato \\ Department of Clinical Biochemistry, Graduate School of Clinical Pharmacy, Kyushu University of Health and Welfare, Nobeoka City, Miyazaki 882-8508, Japan
}

(Received 2 October, 2019; Accepted 2 December, 2019; Published online 19 February, 2020)

\begin{abstract}
Diclofenac, a nonsteroidal anti-inflammatory drug, is commonly used as an antipyretic analgesic owing to its strong antiinflammatory action in clinical treatment. However, diclofenac can cause injury, with gastrointestinal mucosal lesions and skin photosensitivity as the main side effects. In general, photosensitive drugs contain photosensitive chemical sites, and form free radicals under ultraviolet irradiation, leading to phototoxic reactions. Therefore, this study focuses on free radical production in photosensitive reactions of diclofenac. The free radical production mechanism of diclofenac under ultraviolet irradiation, which might result in photo-toxicity, was clarified using a direct electron spin resonance method. When diclofenac was irradiated with ultraviolet light $(254 \mathrm{~nm})$, diclofenac radicals were generated depending on the ultraviolet irradiation time and stably present for $30 \mathrm{~min}$ at room temperature. Diclofenac radicals were produced by the ultraviolet irradiation system depending on the dose of diclofenac until $2 \mathrm{mM}$. Therefore, diclofenac radicals might directly or indirectly react with various biomolecules to cause phototoxicity, other side effects, and new diclofenac pharmacology owing to its stability of diclofenac radicals.
\end{abstract}

Key Words: ESR, diclofenac (DCF), nonsteroidal anti-inflammatory drugs (NSAIDs), UV irradiation, phototoxicity, DCF radical

F ree radicals such as superoxide $\left(\mathrm{O}_{2}{ }^{-}\right)$, hydroxyl radical $\left({ }^{\circ} \mathrm{OH}\right)$, nitric oxide are considered to play important roles in various diseases, including acute lung injury, renal disorder with dialysis, and periodontal disease. ${ }^{(1-7)}$ As controlling inflammation in these pathological states is important, nonsteroidal anti-inflammatory drugs (NSAIDs) are frequently used as general therapeutic agents. $^{(8,9)}$ Although much research on NSAIDs and radicals has been conducted, the detailed reaction mechanism of NSAIDs about radical has yet to be clarified. ${ }^{(10-17)}$

Recently, NSAIDs, especially propionic acid derivatives, have shown phototoxicity. ${ }^{(18-20)}$ Some drugs used to treat human diseases are known to be activated under light irradiation to cause skin rashes, including redness, swelling, and pigmentation. Phototoxic reactions are known to be among the causes of photosensitivity in these drugs, in which agents activated by photochemical reactions cause damage to biochemical components directly or through reactive oxygen species (ROS). ${ }^{(18,19)}$ When a drug molecule absorbs photon energy, electrons are excited from the ground state to the excited state, depending upon the bond type and associated energy level. As the electrons enter different orbitals through photoexcitation and electron pairs are eliminated, the excited electrons have radical properties. Energy transfer from excited drug molecules to oxygen (type-II photochemical reaction) generates singlet oxygen $\left({ }^{1} \mathrm{O}_{2}\right)$, which might participate in the oxidation of membrane lipids and proteins, or induce DNA damage. ${ }^{(20,21)}$ Furthermore, these excited drug molecules might react directly with in vivo molecules (such as DNA, proteins, and cell membranes) though electron or hydrogen transfer (type-I photochemical reaction). ${ }^{(20)}$ Excessive ROS production in the body, can result in the oxidation of nucleic acids, proteins, sugars, and lipids to cause various biological disorders. ${ }^{(22-24)}$

Diclofenac (DCF) is an acetic acid derivative and NSAID that is often used clinically. The action of DCF is particularly strong among NSAIDs, and is characterized by the rapid suppression of pain and heat generation. ${ }^{(25-28)}$ In addition to a strong action, DCF has known clinical side effects, such as causing gastrointestinal and kidney disorders, and phototoxicity. ${ }^{(29-35)}$ However, the detailed mechanism of DCF phototoxicity has yet to be clarified.

Therefore, this study aimed to clarify the reaction mechanism of DCF radical ('DCF) production under ultraviolet (UV) irradiation, which can cause DCF phototoxicity, using a direct electron spin resonance (ESR) method.

\section{Materials and Methods}

Chemicals. DCF was purchased from Wako Pure Chemical Ind. (Tokyo, Japan). 1-Oxyl-2,2,6,6-tetramethyl-4-hydroxypiperidine (TEMPOL) was purchased from TOCRIS Bioscience (Ellisville, MO). Superoxide dismutase from bovine erythrocytes (SOD) was purchased from Wako Pure Chemical Ind. (Osaka, Japan). Water used in these experiments was treated to remove the trace metals by passing through Chelex 100 Resin (Bio-Rad Laboratories, Inc. Hercules, CA) after distillation.

Measurement of diclofenac radical ('DCF) by direct ESR method. DCF was diluted with distilled water in a quartz flat cell $(160 \mu \mathrm{l})$ and, irradiated with UV $(254 \mathrm{~nm})$ using a Handy UV Lamp (SUV-6) (AS ONE, Osaka, Japan). After UV irradiation, ESR spectra were immediately recorded at room temperature in a quartz flat cell using a JEOL JES-FR 30 EX Free Radical Monitor (JEOL, Tokyo, Japan). The operating conditions of the ESR spectrometer were as follows: frequency, $9.42 \mathrm{GHz}$; field, $335.618 \pm$ $5 \mathrm{mT}$; microwave power, $16.0 \mathrm{~mW}$; modulation frequency, $100 \mathrm{kHz}$; modulation width, $0.32 \mathrm{mT}$; amplitude, $7.9 \times 100$; time constant, $0.3 \mathrm{~s}$; and sweep time, $1 \mathrm{~min}$. To identify and determine the amount of radical species ${ }^{\circ} \mathrm{DCF}$, the $g$ value was corrected using the internal Mn marker of the ESR instrument used in this study. The DCF concentration was calculated from a calibration curve prepared from the integrated value of the ESR signal of TEMPOL aqueous solution, for which the spin concentration is known.

*To whom correspondence should be addressed. E-mail: s.aka.roro.noa@gmail.com 


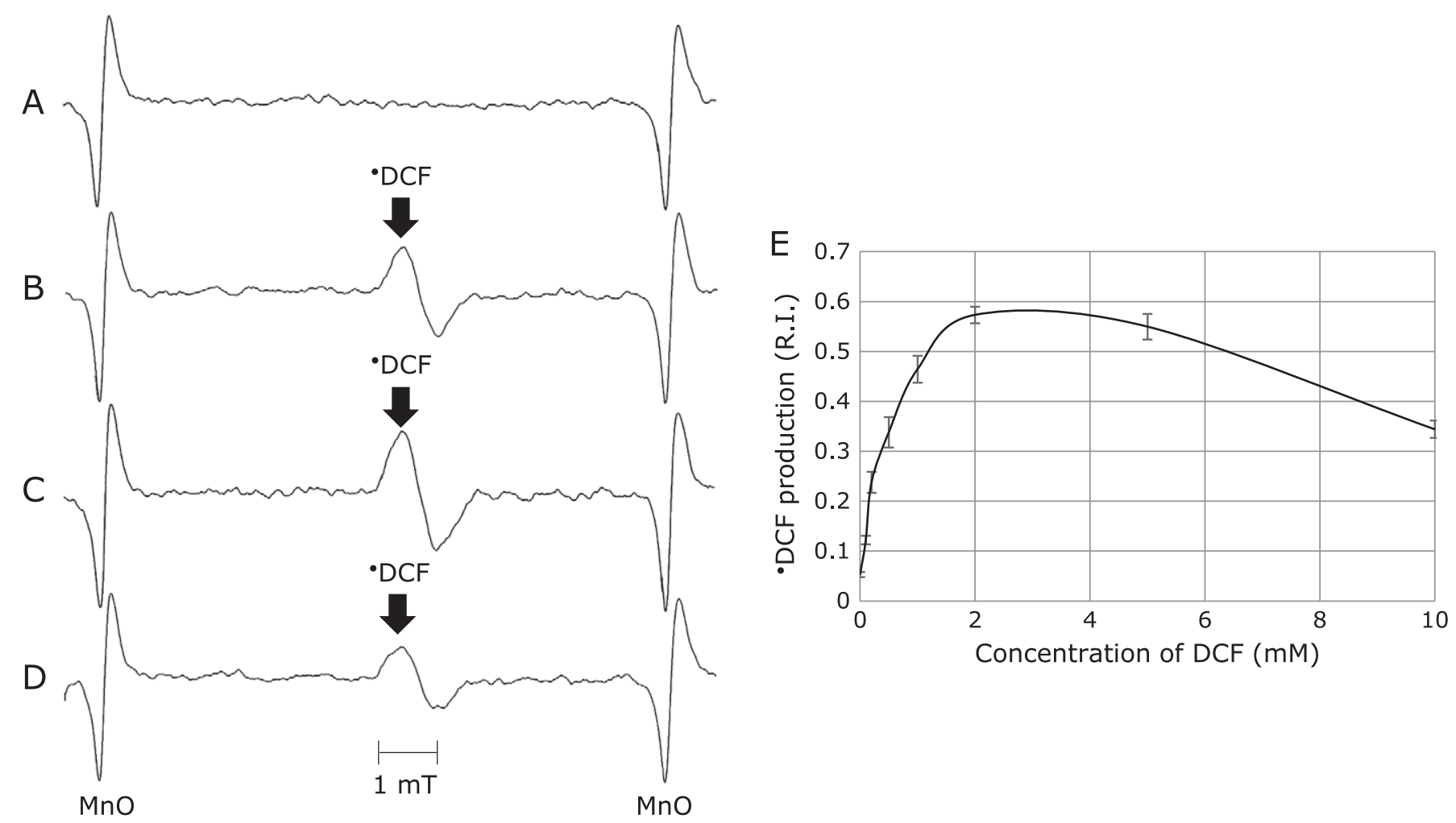

Fig. 1. ESR spectra was measured in various concentration of DCF irradiated with UV $(254 \mathrm{~nm})$ for $3 \mathrm{~min}$. (A) Spectrum obtained in the reaction mixture of $0 \mathrm{mM} \mathrm{DCF}$. (B) Spectrum obtained in the reaction mixture of $1 \mathrm{mM} \mathrm{DCF}$. (C) Spectrum obtained in the reaction mixture of $2 \mathrm{mM}$ DCF. (D) Spectrum obtained in the reaction mixture of $10 \mathrm{mM} \mathrm{DCF}$. (E) ${ }^{\circ} \mathrm{DCF}$ production with dose-dependent manner of DCF. ESR measurement conditions were described in materials and methods. All spectra were recorded after DCF irradiation with UV (254 nm) for 3 min.

Statistical analysis. The statistical significance of the difference was determined by an unpaired Student's $t$ test. Data are expressed as means $\pm \mathrm{SE}$. Differences between groups were considered statistically significant at the level of $p<0.05$.

\section{Result}

ESR spectra and production mechanisms of ${ }^{\circ} \mathrm{DCF}$.

A prominent ESR spectrum of ${ }^{\circ} \mathrm{DCF}$ was observed after UV irradiation $(254 \mathrm{~nm})$ for $3 \mathrm{~min}$ in the absence of $\mathrm{H}_{2} \mathrm{O}_{2}$ (Fig. 1A-D). This represents the first report of ${ }^{\circ} \mathrm{DCF}$ detection using a direct ESR method at room temperature. ${ }^{-D C F}$ increased until $2 \mathrm{mM}$ $\mathrm{DCF}$ in the reactive mixture and then gradually decreased to $10 \mathrm{mM} \mathrm{DCF}$ in the reactive mixture (Fig. 1E). When DCF $(0.1 \mathrm{mM})$ was irradiated with UV $(254 \mathrm{~nm})$, the intensity of ${ }^{\circ} \mathrm{DCF}$ radical generation increased with increasing UV irradiation time (Fig. 2). Increased the amount of ${ }^{\circ} \mathrm{DCF}$ production depending on UV irradiation time could be also observed with other concentrations $(0.1,0.2,0.5,1.0,2.0,5.0$, and $10 \mathrm{mM}$ ) of DCF (data not shown). To evaluate the ${ }^{\circ} \mathrm{DCF}$ production mechanism, we attempted to reduce the amount of dissolved oxygen in the ${ }^{\circ} \mathrm{DCF}$ production system by bubbling with $\mathrm{N}_{2}$. With reduced dissolved oxygen in the DCF solution $(10 \mathrm{mM})$, the ESR peak of ${ }^{\circ} \mathrm{DCF}$ significantly decreased in intensity, but did not disappear (Fig. 3). These results indicated that ${ }^{\circ} \mathrm{DCF}$ was generated even when the oxygen concentration was low.

Time course of ${ }^{-D C F}$. To study the lifetime of ${ }^{-D C F}$, the amount of ${ }^{\circ}$ DCF was measured after UV irradiation $(254 \mathrm{~nm})$ for $3 \mathrm{~min}$. The ${ }^{\circ} \mathrm{DCF}$ peak height obtained by the direct ESR method gradually decreased, but did not disappear, for $30 \mathrm{~min}$ (Fig. 4). DCF was found to be a longer life radical in this instance than $\mathrm{O}_{2}{ }^{--}$and ${ }^{\cdot} \mathrm{OH}$.

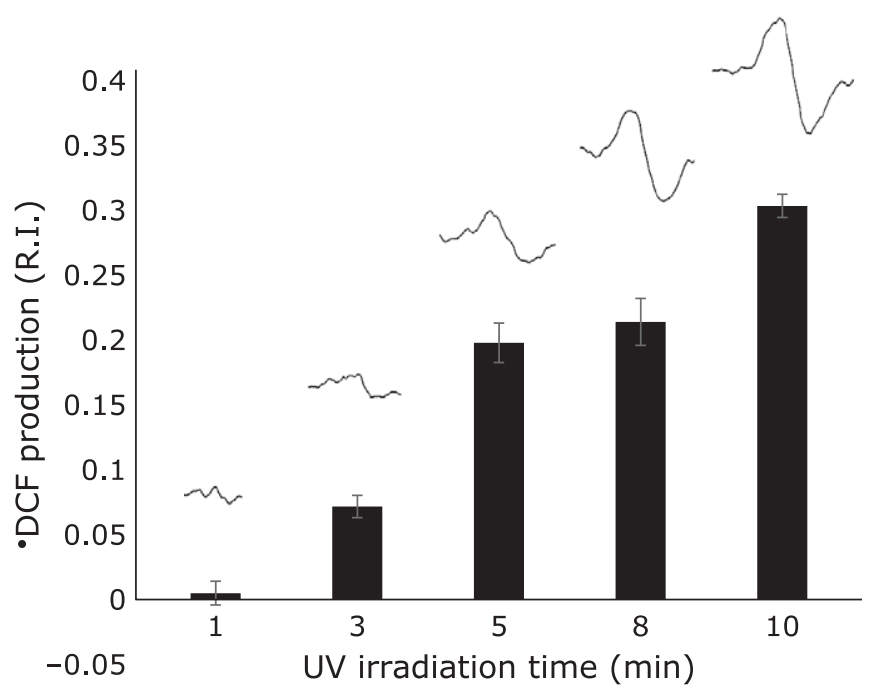

Fig. 2. $D C F$ production with time dependent manner of UV irradiation. ESR signal intensity of ${ }^{\circ} D C F$ were obtained in the reaction system of DCF $(0.1 \mathrm{mM})$, irradiated with UV $(254 \mathrm{~nm})$. ESR measurement condition were as described in materials and methods. Amounts of ${ }^{\circ} D C F$ are expressed as a relative intensity (R.I.) by normalization of the ${ }^{\circ} D C F$ signal height to the standard signal intensity of manganese oxide $(\mathrm{MnO})$ and are the means + SD of three independent experiments $(n=3)$. The waveform and R.I. of the ESR spectra from the 'DCF spin adducts at each UV irradiation time was shown on the figure. Intensity: mean $\pm S D$. 
Reactivity of 'DCF with $\mathrm{O}_{2}{ }^{--}$. To study the effect of $\mathrm{O}_{2}{ }^{--}$on 'DCF production, the amount of ${ }^{\circ} \mathrm{DCF}$ was measured after UV irradiation $(254 \mathrm{~nm})$ for $5 \mathrm{~min}$. The relative intensity of ${ }^{\circ} \mathrm{DCF}$ measured using the direct ESR method increased with the addition of superoxide dismutase (SOD; $100 \mathrm{U} / \mathrm{ml}$ ) (Fig. 5). This result confirmed that ${ }^{\circ} \mathrm{DCF}$ was more likely to be generated without $\mathrm{O}_{2}{ }^{\cdot-}$.

Characteristics of ${ }^{\circ} \mathrm{DCF}$. The spin adducts of radical species -DCF were identified, and their amounts determined. A sharp single $\mathrm{P}_{1}$ signal was obtained at a $g$ value of 2.0038 when DCF $(1 \mathrm{mM})$ was irradiated with UV light $(254 \mathrm{~nm}$ ) for 10 min (Fig. 6). These results showed that ${ }^{\circ} \mathrm{DCF}$ detected under UV irradiation was an oxygen radical. The amount of radicals at this time was determined to be $5.39 \times 10^{7}$ spins. The ${ }^{-} \mathrm{DCF}$ concentration in this system was calculated, to be $1 \mu \mathrm{M}$ comparison with the spins of
TEMPOL radicals. The ${ }^{\circ} \mathrm{DCF}$ concentration was significantly higher, indicating that, ${ }^{-D C F}$ might cause tissue injury directly.

\section{Discussion}

In this study, we obtained direct evidence that DCF forms extremely stable DCF under UV irradiation. This represents the first evidence of stable ${ }^{\circ} \mathrm{DCF}$ detection in a UV irradiation system using direct ESR method.

Kawaguchi et al. ${ }^{(36)}$ previously estimated that the photolysate of DCF was cyclized and radicalized at the center of the molecule by LC-NMR analysis, which was in agreement with our results. LC-NMR analysis provides detailed information on substance structure, but information on unpaired electrons is difficult to

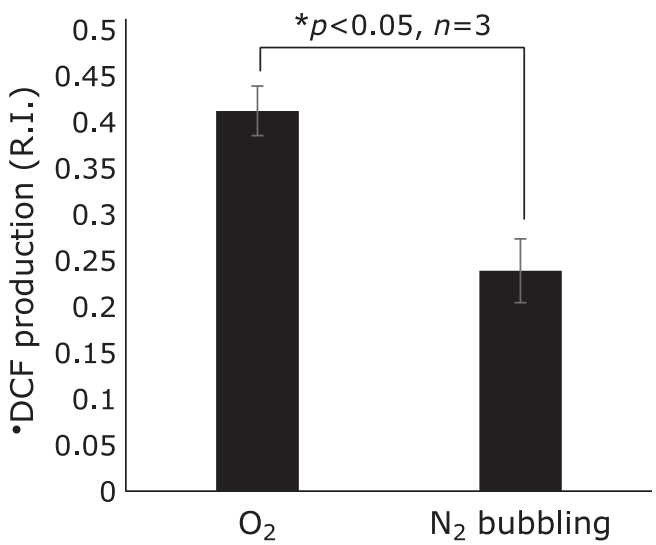

Fig. 3. Effect of dissolved $\mathrm{O}_{2}$ on $\cdot \mathrm{DCF}$ formation. For the treatment of DCF (1 mM), dissolved oxygen was reduced with $\mathrm{N}_{2}$ bubbling. Each of those substituted with $\mathrm{N}_{2}$ and those not substituted with $\mathrm{N}_{2}$ low concentration of $\mathrm{O}_{2}$ was irradiated with UV $(254 \mathrm{~nm})$ for $3 \mathrm{~min}$, and then measured by ESR. ESR measurement conditions were as described in materials and methods. Intensity: mean \pm SD. ${ }^{*} p<0.05$.

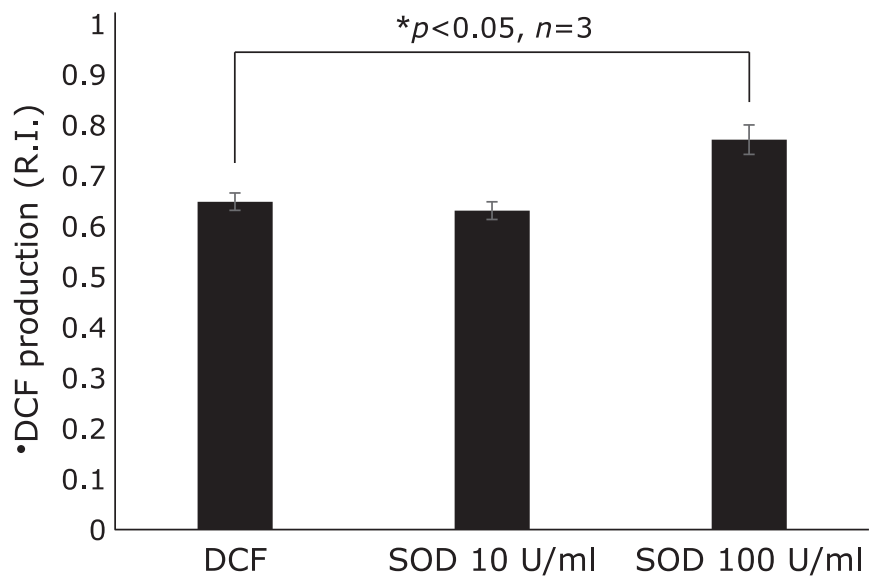

Fig. 5. Effects of superoxide dismutase (SOD) on ${ }^{\circ} D C F$ formation. After adjustment of DCF (final conc. $1 \mathrm{mM}$ ), SOD (final conc. $10 \mathrm{U} / \mathrm{ml}, 100 \mathrm{U} /$ $\mathrm{ml}$ ) was added removing the $\mathrm{O}_{2}{ }^{-}$. Each sample with SOD was irradiated with UV ( $254 \mathrm{~nm}$ ) for $5 \mathrm{~min}$, and then measured by ESR. ESR measurement conditions were as described in materials and methods. Intensity: mean \pm SD. ${ }^{*} p<0.05$.

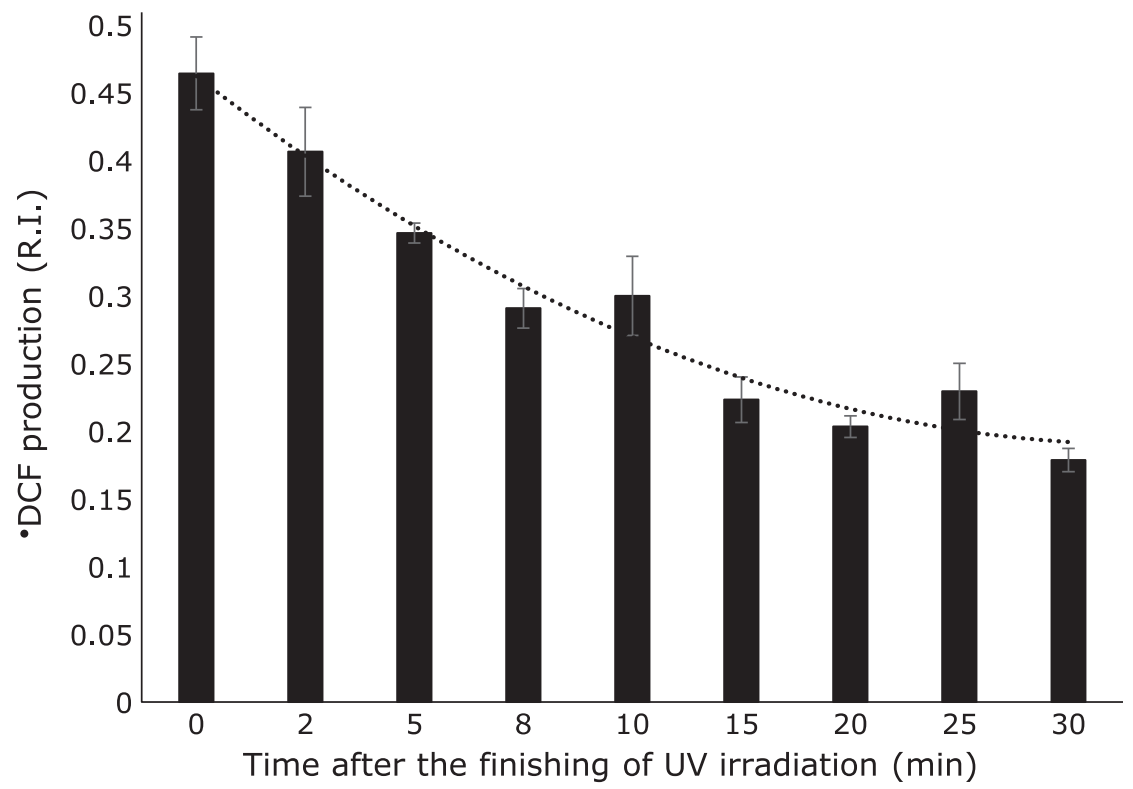

Fig. 4. Time course of ${ }^{\circ} D C F$ spin adducts generation from the finishing of the UV irradiation. The ESR spectrum of ${ }^{\circ} D C F$ spin adducts were obtained from the finishing of the irradiating DCF $(1 \mathrm{mM})$ with UV $(254 \mathrm{~nm})$ for $3 \mathrm{~min}(n=3)$. ESR measurement conditions were as described in materials and methods. Intensity: mean \pm SD. 


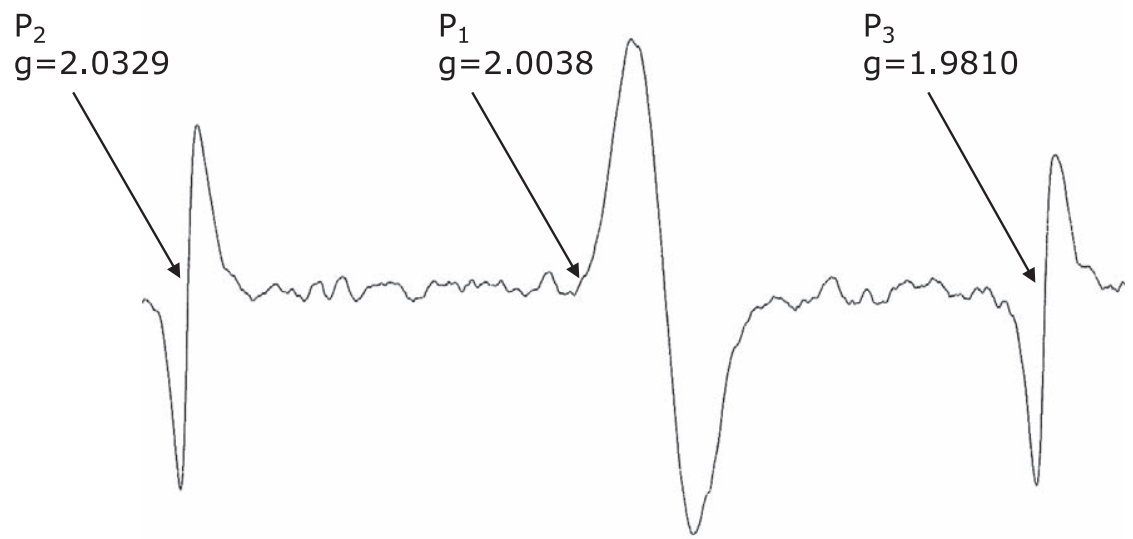

Fig. 6. ESR spectrum and $g$ value of ${ }^{\circ} D C F$ spin adducts. The ESR spectrum and $g$ value from ${ }^{\circ} D C F$ spin adducts were obtained in the system of DCF $(1 \mathrm{mM})$, irradiated with UV $(254 \mathrm{~nm})$ for $10 \mathrm{~min}$. $P_{1}$ is a single signal derived from ${ }^{\circ} D C F$. $P_{2}$ is the $3 r d$ signal and $P_{3}$ is the 4 th signal of internal Mn marker of ESR. ESR measurement conditions were as described in Materials and Methods.

obtain using this method. Therefore, in this study, we elucidated the mechanism of ${ }^{\circ}$ DCF formation using a direct ESR method.

Our results, showed that ${ }^{\circ} \mathrm{DCF}$ generation was dependent on the DCF concentration until $2 \mathrm{mM}$, but on the UV irradiation time, and that the radical species might be an alkoxyl radical or a nitrogen radical based on the $g$ value (2.0038). In order to identify radical species, it need to be further examination of $g$ value using more useful internal marker as well as of the hyperfine structure of the ESR spectrum with smaller modulation width.

Assuming that ${ }^{\circ} \mathrm{CF}$ is an alkokyl radical, we showed that electron transfer from ${ }^{\circ} \mathrm{DCF}$ to $\mathrm{O}_{2}$ hardly occurred because the amount of DCF production decreased with $\mathrm{N}_{2}$ bubbling [see equation (1)].

$$
\cdot \mathrm{DCF}+\mathrm{O}_{2} \rightleftarrows \mathrm{DCF}+\mathrm{O}_{2}^{\cdot-}
$$

Furthermore, we showed that electron transfer from ${ }^{\circ} \mathrm{DCF}$ to $\mathrm{O}_{2}{ }^{\cdot-}$ occurred because the amount of ${ }^{\circ}$ DCF produced increased with the addition of SOD [see equation (2)]. Besides, when ascorbic acid (ASA) as a scavenger of ${ }^{\circ} \mathrm{OH}$ and $\mathrm{O}_{2}{ }^{-{ }^{-}}$was added to the complete reaction mixture, ASA strongly suppressed ${ }^{\circ} \mathrm{DCF}$ production. Therefore, it might be suggested that ${ }^{\circ} \mathrm{OH}$ play important role in the production of ${ }^{\circ}$ DCF (data not shown).

$$
\cdot \mathrm{DCF}+\mathrm{O}_{2}{ }^{\cdot-}+2 \mathrm{H}^{+} \rightarrow \mathrm{DCF}+\mathrm{H}_{2} \mathrm{O}_{2}
$$

Accordingly, ${ }^{\circ}$ DCF can be assumed to exist for a unusually long time compared with other radicals. Free radicals with unpaired electrons are known to be very unstable, for example, $\mathrm{O}_{2}{ }^{-}$and ${ }^{\circ} \mathrm{OH}$ have half-lives of $10^{-6}$ and $10^{-9} \mathrm{~s}$, respectively. In this study, the stability of ${ }^{\circ} \mathrm{DCF}$ did not change, even at low $\mathrm{O}_{2}$ concentrations, suggesting that ${ }^{\circ} \mathrm{DCF}$ would be present not only in blood vessels with relatively high $\mathrm{O}_{2}$ levels, but also in tissues with low $\mathrm{O}_{2}$ levels. Therefore, it is possible that ${ }^{-} \mathrm{DCF}$ acts as a toxic radical, both in the periphery and in the blood vessels. In contrast, DCF, reducing radicals, scavenge oxidative radicals and act as proactive.

In any other possible knowledge, DCF is a secondary amine, which generally act as an electron donor. It is possible that the

\section{References}

1 Sato $\mathrm{K}$, Kadiiska MB, Ghio AJ, et al. In vivo lipid-derived free radical formation by NADPH oxidase in acute lung injury induced by lipopolysaccharide: a model for ARDS. FASEB J 2002; 16: 1713-1720.

2 Sato K, Corbett J, Mason RP, Kadiiska MB. In vivo evidence of free radical excited state of DCF may reduce molecular oxygen to produce the DCF radical cation and $\mathrm{O}_{2}^{-{ }^{-}}$. The DCF radical cation may undergo deprotonation to produce $\mathrm{DCF}$, which is a nitrogen radical. In such a case, molecular oxygen act as an oxidant to generate ${ }^{\circ} \mathrm{DCF}$. Nitrogen bubbling may decrease the oxidant, i.e., molecular oxygen, leading to the decrease of ${ }^{\circ} \mathrm{DCF}$ production. SOD converts $\mathrm{O}_{2}^{--}$to molecular oxygen and water. The oxidant (molecular oxygen) to produce $\mathrm{DCF}$ may be recycled in the presence of SOD, leading to the increase of ${ }^{\circ} \mathrm{DCF}$ production. In future examination, the hyperfine structure of the ESR spectrum of ${ }^{\circ} \mathrm{DCF}$ will provide detailed information about the electronic structure as well as production mechanism of ${ }^{\circ} \mathrm{DCF}$.

DCF generation in vivo is still unknown, which indicate the need for further studies. We propose that ${ }^{\circ} \mathrm{DCF}$ is generated in vivo because in a previous study by Miura ${ }^{(37)}$ and Muraoka ${ }^{(38)}$ showed that NSAIDs react with peroxidase to possibly generate NSAID radicals ('NSAID). Previously, for both the intended and side effects of NSAID inhibition of cyclooxygenase (COX), the main mechanism has been considered to involve changes in the balance of eicosanoids. ${ }^{(39-41)}$ However, this report suggests that radical formation, not only by DCF, but also by other NSAIDs is needed for physiological effects other than COX inhibition.

In conclusion, ${ }^{\circ} \mathrm{DCF}$ might generate via one-electron reduction of DCF in vivo or in human. Furthermore, the generated ${ }^{\circ C F}$ might affect the various diseases where DCF is frequently used for treatment, ${ }^{(1-7)}$ such as inflammation, cancer, or orthopedic disorders. Therefore, it was suggested that our detected ${ }^{\circ} \mathrm{DCF}$ might have important roles in various diseases.

\section{Acknowledgments}

We thank Simon Partridge, PhD, from Edanz Group (www.edanzediting.com/ac) for editing a draft of this manuscript. We also thank Ryuta Kawamoto and Yuji Miyazaki for experimental assist.

\section{Conflict of Interest}

No potential conflicts of interest were disclosed.

generation in the mouse lung after exposure to Pseudomonas aeruginosa bacterium: an ESR spin-trapping investigation. Free Radic Res 2012; 46: 645-655.

3 Ueda A, Nagai K, Hirayama A, Saito C, Yamagata K. Peritoneal dialysis 
preserves residual renal function and reduces oxidative stress during the initial period of dialysis therapy. Adv Perit Dial 2017; 33: 18-21.

4 Hirayama A, Nagase S, Gotoh M, et al. Reduced serum hydroxyl radical scavenging activity in erythropoietin therapy resistant renal anemia. Free Radic Res 2002; 36: 1155-1161.

5 Komatsu T, Lee M-C. Oxidative stress and periodontal disease in Down syndrome. In: Ekuni D, Battino M, Tomofuji T, Putnins EE, eds. Studies on Periodontal Disease Oxidative Stress in Applied Basic Research and Clinical Practice, New York: Human Press Springer, 2014; 211-214.

6 Komatsu T, Lee MC, Miyagi A, et al. Reactive oxygen species generation in gingival fibroblasts of Down syndrome patients detected by electron spin resonance spectroscopy. Redox Rep 2006; 11: 71-77.

7 Yoshida A, Yoshino F, Makita T, et al. Reactive oxygen species production in mitochondria of human gingival fibroblast induced by blue light irradiation. J Photochem Photobiol B 2013; 129: 1-5.

8 Tanaka K, Ishihara T, Sugizaki T, et al. Mepenzolate bromide displays beneficial effects in a mouse model of chronic obstructive pulmonary disease. Nature Commun 2013; 4: 2686-2698.

9 Hirayama A, Okamoto T, Kimura S, et al. Kangen-karyu raises surface body temperature through oxidative stress modification. J Clin Biochem Nutr 2016; 58: $167-173$

10 Ghiselli A, Laurenti O, De Mattia G, Maiani G, Ferro-Luzzi A. Salicylate hydroxylation as an early marker of in vivo oxidative stress in diabetic patients. Free Radic Biol Med 1992; 13: 621-626.

11 Zentella de Piña M, Saldaña-Balmori Y, Hernández-Tobías A, Piña E. Nonsteroidal antiinflammatory drugs lower ethanol-mediated liver increase in lipids and thiobarbituric acid reactive substances. Alcohol Clin Exp Res 1993; 17: $1228-1232$.

12 Takayama F, Egashira T, Yamanaka Y. Effect of diclofenac, a non-steroidal anti-inflammatory drug, on lipid peroxidation caused by ischemia-reperfusion in rat liver. Jpn J Pharmacol 1994; 64: 71-78.

13 Gupta SK, Joshi S. Role of naproxen as anti-oxidant in selenite cataract. Ophthalmic Res 1994; 26: 226-231.

14 Bilodeau JF, Wang M, Chung FL, Castonguay A. Effects of nonsteroidal antiinflammatory drugs on oxidative pathways in A/J mice. Free Radic Biol Med 1995; 18: 47-54.

15 Muraoka S, Miura T. Inactivation of creatine kinase during the interaction of mefenamic acid with horseradish peroxidase and hydrogen peroxide: participation by the mefenamic acid radical. Life Sci 2003; 72: 1897-1907.

16 Saito R, Tamura M, Matsui H, et al. Qing Dai attenuates nonsteroidal antiinflammatory drug-induced mitochondrial reactive oxygen species in gastrointestinal epithelial cells. J Clin Biochem Nutr 2015; 56: 8-14.

17 Ito H, Matsui H, Hirayama A, Indo HP, Majima HJ, Hyodo I. Reactive oxygen species induced by non-steroidal anti-inflammatory drugs enhance the effects of photodynamic therapy in gastric cancer cells. J Clin Biochem Nutr 2016; 58: 180-185.

18 Ferguson J, Addo HA, McGill PE, Woodcock KR, Johnson BE, Frain-Bell W. A study of benoxaprofen-induced photosensitivity. Br J Dermatol 1982; 107: 429-441.

19 Epstein JH, Wintroub BU. Photosensitivity due to drugs. Drugs 1985; 30: 42-57.

20 Pathak MA. Molecular aspects of drug photosensitivity with special emphasis on psoralen photosensitization reaction. J Natl Cancer Inst 1982; 69: 163-170.

21 Foote CS, Shook FC, Abakerli RB. Characterization of singlet oxygen. Methods Enzymol 1984; 105: 36-47.

22 Sodum RS, Fiala ES. Analysis of peroxynitrite reactions with guanine, xanthine, and adenine nucleosides by high-pressure liquid chromatography with electrochemical detection: C8-nitration and -oxidation. Chem Res Toxicol 2001; 14: 438-450.
23 Stoyanovsky DA, Tyurina YY, Tyurin VA, et al. Thioredoxin and lipoic acid catalyze the denitrosation of low molecular weight and protein $S$-nitrosothiols. J Am Chem Soc 2005; 127: 15815-15823.

24 Totter JR. Spontaneous cancer and its possible relationship to oxygen metabolism. Proc Natl Acad Sci U S A 1980; 77: 1763-1767.

25 Cryer B, Feldman M. Cyclooxygenase-1 and cyclooxygenase-2 selectivity of widely used nonsteroidal anti-inflammatory drugs. Am J Med 1998; 104: 413-421.

26 Menassé R, Hedwall PR, Kraetz J, et al. Pharmacological properties of diclofenac sodium and its metabolites. Scand J Rheumatol Suppl 1978; 22: 516.

27 Tsurumi K, Hiramatsu Y, Yamaguchi A, Hayashi M, Shibuya T. Antiinflammatory action of $\mathrm{N}$-(2,6-dichlorophenyl)-o-aminophenylacetic acid, its sodium salt, N-(2,6-dichlorophenyl)-anthranilic acid and its sodium salt. 2. On subacute inflammation. Nihon Yakurigaku Zasshi 1973; 69: 319-334.

28 Stacher G, Steinringer H, Schneider S, Mittelbach G, Winklehner S, Gaupmann G. Experimental pain induced by electrical and thermal stimulation of the skin in healthy man: sensitivity to 75 and $150 \mathrm{mg}$ diclofenac sodium in comparison with $60 \mathrm{mg}$ codeine and placebo. Br J Clin Pharmacol 1986; 21 : 35-43.

29 Somerville K, Faulkner G, Langman M. Non-steroidal anti-inflammatory drugs and bleeding peptic ulcer. Lancet 1986; 1: 462-464.

30 Langman MJS. Peptic ulcer complications and the use of non-aspirin nonsteroidal anti-inflammatory drugs. Adverse Drug Reaction Bulletin 1986; 120: $448-451$.

31 Savage RL, Moller PW, Ballantyne CL, Wells JE. Variation in the risk of peptic ulcer complications with nonsteroidal antiinflammatory drug therapy. Arthritis Rheum 1993; 36: 84-90.

32 Ungprasert P, Cheungpasitporn W, Crowson CS, Matteson EL. Individual non-steroidal anti-inflammatory drugs and risk of acute kidney injury: a systematic review and meta-analysis of observational studies. Eur J Intern Med 2015; 26: 285-291.

$33 \mathrm{Ng}$ LE, Vincent AS, Halliwell B, Wong KP. Action of diclofenac on kidney mitochondria and cells. Biochem Biophys Res Commun 2006; 348: 494-500.

34 Becker L, Eberlein-König B, Przybilla B. Phototoxicity of non-steroidal antiinflammatory drugs: in vitro studies with visible light. Acta Derm Venereol 1996; 76: 337-340.

35 Encinas S, Bosca F, Miranda MA. Phototoxicity associated with diclofenac: a photophysical, photochemical, and photobiological study on the drug and its photoproducts. Chem Res Toxicol 1998; 11: 946-952.

36 Kawaguchi K, Nakano T, Kimura K. How do you use liquid chromatographynuclear magnetic resonance (LC-NMR) effectively for structural determinations of pharmaceutical impurities and metabolites? Chromatography 2011; 32: $171-179$

37 Miura T. Direction of strategic use: a new classification of non-steroidal antiinflammatory drugs based on reactivity with peroxidase. Yakugaku Zasshi 2013; 133: 681-689.

38 Muraoka S, Miura T. Metabolism of non-steroidal anti-inflammatory drugs by peroxide: implication for gastrointestinal mucosal lesions. Yakugaku Zasshi 2007; 127: 749-756.

39 Bunting S, Moncada S, Vane JR. The prostacyclin--thromboxane A2 balance: pathophysiological and therapeutic implications. Br Med Bull 1983; 39: 271276.

40 Sanak M, Simon HU, Szczeklik A. Leukotriene C4 synthase promoter polymorphism and risk of aspirin-induced asthma. Lancet 1997; 350: 1599-1600.

41 Higashi N, Taniguchi M, Mita H, Higashi A, Akiyama K. Aspirin-induced urticaria and angioedema, but not bronchoconstriction, associated with cysteinyl leukotriene overproduction in 2 patients with asthma. J Allergy Clin Immunol 2002; 110: 666-667. 